\title{
Syndactyly type 2
}

INSERM

\section{Source}

INSERM. (1999). Orphanet: an online rare disease and orphan drug data base. Syndactyly type 2. ORPHA:93403

Syndactyly type 2 or synpolydactyly (SPD) is a rare congenital distal limb malformation characterized by the combination of syndactyly and polydactyly. 